\title{
The Stability of Dummy Variable Price Measures \\ Obtained from Hedonic Regressions
}

\author{
Ana Aizcorbe \\ Federal Reserve Board \\ Mail Stop 153 \\ Washington, DC 20551 \\ Ana.M.Aizcorbe@frb.gov \\ February 6, 2003 \\ JEL CODES: C43, C20, O47
}

\begin{abstract}
Although the stability of coefficients from hedonic regressions has received much attention recently, that of dummy variable (DV) price indexes obtained from these regressions has not. In principle, one problem translates into the other only when some prices are not observed in the data. Numerically, however, DV measures obtained from a "typical" specification can be quite unstable even when the number of missing prices is small. To the extent that collinearity is an important source of the problem, functional forms that use (orthogonal) fixed effects to control for quality differences across goods should yield more stable estimates. Data for Intel's microprocessors are used to illustrate these points.
\end{abstract}

I thank Nathan Musick, Marshall Reinsdorf, Jack Triplett and my colleagues at the Board for very useful comments. The views in this paper are those of the author and do not represent the views of the Board of Governors or the staff at the Federal Reserve System. 


\section{Introduction}

A typical hedonic regression explains prices of individual models as a function of the model's characteristics and time dummies. ${ }^{1}$ Empirical work has proven the estimated coefficients for the model's characteristics to be notoriously unstable; models' characteristics are typically highly correlated and it is believed that collinearity contributes importantly to the instability (see, for example, Dulberger(1989), Berndt, Dulberger and Rappaport(2000) and Pakes(2002)). However, there is little evidence on the stability of price measures calculated using the coefficients on the time dummies (see Heravi and Silver(2002) for an important exception). This is an important omission because generating these "dummy variable" (DV) price measures is arguably the most common use of hedonic regressions in the academic literature.

This note first summarizes what is known about the stability of DV price measures viz a viz that of the coefficients on the characteristics (referred to as "hedonic coefficients" below). Namely, DV price measures are only a function of hedonic coefficients in time periods when some of the individual price relatives are unobserved. In those cases, the DV price measure includes an implicit imputation for the missing prices that is based on the hedonic coefficients, and the stability of the DV measure will depend on the stability of the hedonic coefficients. In contrast, when all prices are observed, the DV measure is numerically equivalent to an index-and is immune to any instability in the hedonic coefficients.

An empirical example shows that the stability of both measures depends importantly on the particular specification given to the hedonic regression. Moreover, it is shown that a functional form that uses fixed effects to control for quality differences across models can provide remarkably stable coefficients for DV measures. This specification--advocated by Diewert(2001) and used by Aizcorbe, Corrado, and Doms(2000)_avoids potential collinearity problems because the fixed effects are, by construction, orthogonal. Admittedly, this specification has limited usefulness in applications where one wishes to estimate the effects of each characteristic on prices. But, if all one wants is a DV measure of price change, all one really needs is a way to control for potential differences across models and this specification does just that.

\section{Stability of the DV Price Measure}


What is known about the relationship between the DV price measure and hedonic coefficients may be summarized in the context of a simple, but typical, hedonic regression specification: ${ }^{2,3}$

$$
\ln \mathrm{P}_{\mathrm{m}, \mathrm{t}}=\beta+\beta_{2}\left(\mathrm{C}_{\mathrm{m}}\right)+\beta_{3}\left(\mathrm{C}_{\mathrm{m}}\right)^{2}+\Sigma_{\mathrm{s}=1, \mathrm{~T}} \gamma_{\mathrm{s}} \mathrm{D}_{\mathrm{s}}+\varepsilon_{\mathrm{m}, \mathrm{t}}
$$

where the (logged) price of each model at each point in time $\left(\ln \mathrm{P}_{\mathrm{m}, \mathrm{t}}\right)$ is assumed to be a quadratic function of the characteristics (only one characteristic in this simplified version) and "models" are defined to be homogeneous over time, so that $\mathrm{C}_{\mathrm{m}, \mathrm{t}}=\mathrm{C}_{\mathrm{m}}$, for all $\mathrm{t}$. When models are defined in this way, quality change occurs only when new models are introduced and old models exit the market and not over a particular model's lifetime. All other influences are relegated to time dummies: $\mathrm{D}_{\mathrm{s}}$ is an indicator that equals one when $\mathrm{s}=\mathrm{t}$.

As in most log-linear specifications, the (logged) DV measure of price change between time $t$ and time $t-1$ is the difference in the time dummies from the two periods:

$$
\mathrm{DV}_{\mathrm{t}, \mathrm{t}-1}=\left(\gamma_{\mathrm{t}}-\gamma_{\mathrm{t}-1}\right)
$$

This is a constant-quality measure of aggregate price change because the observed characteristics in the hedonic regression have control for quality differences across models.

The DV price measure is a function of the (potentially unstable) hedonic coefficients when some prices are missing in the period under study. The easiest way to see this is to consider the results from two regressions. Regression 1 uses data from two time periods, $t$ and $t-$ 1. Regression 2 adds a third time period $t+1$ to the dataset. Both regressions are used to measure price change from t-1 to t; the difference is they do so with different data. Estimates for the time dummies from the first regression $\left(\gamma_{t}^{1}\right)$ can be written:

$$
\gamma_{t}^{1}=\Sigma_{m \varepsilon M(t)} \ln P_{m, t}-\Sigma_{m \varepsilon M(t)}\left(b^{1}+b^{1}{ }_{2}\left(C_{m}\right)+b^{1}{ }_{3}\left(C_{m}\right)^{2}\right),
$$

where $M(t)$ denotes the models whose prices are observed at time $t, \Sigma_{\mathrm{meM}(\mathrm{t})}$ denotes a sum taken over those models, and the $\mathrm{b}^{1}$, s are the estimated parameters. This expression says that the time 
dummy coefficient is a geometric mean of the prices for each model less terms that control for quality differences across models. The corresponding DV measure from this regression for the $t$, $\mathrm{t}-1$ time period is the difference between the two time dummies $\left(\gamma_{\mathrm{t}}^{1}-\gamma_{\mathrm{t}-1}^{1}\right)$ :

$$
\begin{aligned}
& \mathrm{DV}_{\mathrm{t}, \mathrm{t}-1}^{1}= \Sigma_{\mathrm{m \varepsilon M}(\mathrm{t})} \ln \mathrm{P}_{\mathrm{m}, \mathrm{t}}-\Sigma_{\mathrm{m \varepsilon M}(\mathrm{t})}\left(\mathrm{b}^{1}+\mathrm{b}_{2}{ }_{2}\left(\mathrm{C}_{\mathrm{m}}\right)+\mathrm{b}_{3}{ }_{3}\left(\mathrm{C}_{\mathrm{m}}\right)^{2}\right) \\
&-\left[\Sigma_{\mathrm{m \varepsilon M}(\mathrm{t}-1)} \ln \mathrm{P}_{\mathrm{m}, \mathrm{t}-1}-\Sigma_{\mathrm{m} \varepsilon \mathrm{M}(\mathrm{t}-1)}\left(\mathrm{b}^{1}+\mathrm{b}^{1}{ }_{2}\left(\mathrm{C}_{\mathrm{m}}\right)+\mathrm{b}^{1}{ }_{3}\left(\mathrm{C}_{\mathrm{m}}\right)^{2}\right)\right]
\end{aligned}
$$

If all prices are observed, the terms that include the characteristics will cancel out (i.e., $\mathrm{M}(\mathrm{t})=\mathrm{M}(\mathrm{t}-1)$ and the sums are taken over the same models), and the DV measure boils down to a difference of means. ${ }^{4}$ In that case, any instability in the b's does not translate into unstable DV measures.

However, suppose that the price for good " $\mathrm{X}$ " is not observed at time $\mathrm{t}$, either because it is simply missing in the data or because the good exited at time $t$. The DV measure constructed from each regression contains an imputed price relative for good X. For the $i^{\text {th }}$ regression, the DV measure is:

$$
\mathrm{DV}_{\mathrm{t}, \mathrm{t}-1}^{\mathrm{i}}=\sum_{\mathrm{m} \varepsilon \mathrm{M}(\mathrm{t}-1)} \ln \mathrm{P}_{\mathrm{m}, \mathrm{t}}-\sum_{\mathrm{m} \varepsilon \mathrm{M}(\mathrm{t}-1)} \ln \mathrm{P}_{\mathrm{m}, \mathrm{t}-1}+\left[\ln \mathrm{P}_{\mathrm{X}, \mathrm{t}-1}-\left(\mathrm{b}^{\mathrm{i}}+\mathrm{b}_{2}^{\mathrm{i}}\left(\mathrm{C}_{\mathrm{X}}\right)+\mathrm{b}_{3}^{\mathrm{i}}\left(\mathrm{C}_{\mathrm{X}}\right)^{2}\right)\right] .
$$

and the imputed price relative for good X (the term in square brackets) depends on the estimated coefficients. Therefore, DV measures obtained from regressions that use different time periods can differ when some prices are missing. For two regressions, regressions 1 and 2, the difference in the two DV measures for price change from $\mathrm{t}$ to $\mathrm{t}-1$ is:

$$
\mathrm{DV}_{\mathrm{t}, \mathrm{t}-1}^{2}-\mathrm{DV}_{\mathrm{t}, \mathrm{t}-1}^{1}=\left(\mathrm{b}^{2}-\mathrm{b}^{1}\right)+\left(\mathrm{b}^{2}{ }_{2}-\mathrm{b}_{2}{ }_{2}\right) \mathrm{C}_{\mathrm{X}}+\left(\mathrm{b}_{3}{ }_{3}-\mathrm{b}_{3}{ }_{3}\right)\left(\mathrm{C}_{\mathrm{X}}\right)^{2}
$$

The magnitude of the difference in the two measures is an empirical issue; in principle, the differences in the coefficients could be positive or negative and their combined effects could be small or large. Moreover, in this example, only one good required an imputed price (good X), whereas, in general, there may be many such goods and, in those cases, the sensitivity of DV measures will also depend on how many of the observations required imputations. 


\section{Empirical Illustration}

The stability of DV price measures is explored empirically using data from Aizcorbe, Corrado and Doms (2000). The data are a panel of near-universe observations on prices and characteristics for Intel's microprocessor chips at quarterly frequencies from 1993 to 1999. When each model is defined to be homogeneous--such that its characteristics do not change over time--one can track the prices for each chip, so defined, over the life of the chip. As discussed in Aizcorbe, Corrado and Doms(2000), the only missing prices in these data are those associated with turnover and most time periods have relatively few births or deaths.

The "typical" hedonic specification shown in (1) is used to explore the potential magnitude of instability in the hedonic coefficients and its potential effect on the DV measures. In the specification, prices for microprocessors are assumed to be a quadratic function of the speed of the chip (MHz) and time dummies. ${ }^{5}$ Table 1 shows that the estimated coefficients from this specification are quite unstable. Each column of the table gives results from a different regression, where each regression adds an additional year of data. So, for example, the first column--regression (1)--gives the coefficient estimates from a regression that uses data from 1993-94, the second column--regression (2)--adds data from 1995, and so on.

The second and third row show the coefficients on the MHz characteristics. As may be seen, these coefficients are quite sensitive to changes in the underlying dataset. The coefficients on $\mathrm{MHz}$ vary from .086 in regression (1) to .026 in regression (6) and those on the squared term vary from -.00008 in regression (3) to -.0002 in regression (2). The remaining rows give estimated coefficients for the quarterly dummies. Descriptive statistics for these coefficient estimates are given in the last three columns. Again, the standard error over most of these coefficient values is quite high-excluding a few outliers, they range from about 10 to 50 percent of their respective means.

Table 2 provides the DV measures calculated from these time dummies, measured as quarter-to-quarter percent changes in prices and calculated using differences in time dummies as in (2). Except for three observations where all prices are observed--93Q4, 94Q3 and 94Q4, in italics--the price measures vary substantially. For example, for 98Q4, the DV measure from regression (5) is about half the magnitude as the same DV measure estimated using regression (6) (a 10 percent drop in prices vs. a 19 percent drop). Similarly, the DV measures for 93q3 vary from 4 percent — in regression (1) — to nearly 19 percent — in regression (6). 
These large differences are surprising because the number of turnover observations in any one quarter is small in this data set. The differences are also troublesome because most datasets will likely involve more missing prices; other datasets will likely contain more turnover observations and/or may be more sparse than this near-universe dataset. The remainder of this section explores the use of a functional form that generates more stable DV measures.

The lack of stability in hedonic coefficients has been largely attributed to collinearity problems. In the specification used above, the $\mathrm{MHz}$ and $\mathrm{MHz}$ squared variables are highly correlated. More generally, though, observed characteristics of goods tend to move together. For microprocessors, the faster chips also tend to have other enhancements: larger cache, faster external bus, etc. Another example is the automobile, where the size of the vehicle is highly correlated with the weight of the vehicle, the size of the engine, and many other attributes that affect prices. This lack of variation across characteristics gives rise to collinearity among the explanatory variables and instability in the parameters.

A functional form advocated by Diewert(2001) and used by Aizcorbe, Corrado and Doms (2000) can be used to avoid these collinearity problems. That functional form uses fixed effects (rather than characteristics) to control for quality differences across models:

$$
\ln \mathrm{P}_{\mathrm{m}, \mathrm{t}}=\alpha_{\mathrm{m}} \mathrm{D}_{\mathrm{m}}+\Sigma_{\mathrm{s}=1, \mathrm{~T}} \gamma_{\mathrm{s}} \mathrm{D}_{\mathrm{s}}+\varepsilon_{\mathrm{m}, \mathrm{t}}
$$

where $\mathrm{D}_{\mathrm{m}}$ is an indicator variable that identifies models. One can obtain the more typical specification in (1) by imposing $\alpha_{m} D_{m}=\beta+\beta_{2}\left(C_{m}\right)+\beta_{3}\left(C_{m}\right)^{2}$ on (7). ${ }^{6}$ The fixed effects specification is more general than the usual specification because it does not impose any functional form assumptions on how the characteristics affect price. As noted in Diewert(2001), this functional form is essentially, non-parametric--and, hence, helps avoid potential misspecification errors that could also generate unstable parameters.

Importantly, this specification avoids potential collinearity problems because the model dummies are orthogonal. This specification has limited usefulness in applications where one needs to estimate the effects of each characteristic on prices. But, if all one wants is a DV measure of price change, this specification certainly provides a way to control for potential differences across models.

The coefficient estimates and DV measures obtained from this specification are 
considerably more stable than those in the typical specification. The coefficients of variation on the fixed effect coefficients never exceed $6 \%$ and average about $2 \%$ (chart 1) whereas the comparable coefficients of variation from the typical regression are $47 \%$ (for the $\mathrm{MHz}$ coefficient) and $109 \%$ (for the $\mathrm{MHz}^{2}$ coefficient). The DV price measures are also more stable than those using the typical specification (table 3). Except for three time periods where large differences appear--97q1, 97q3, and 97q4--the differences are small: the coefficient of variation is less than 6 percent and, in the majority of cases, less than 1 percent. $^{7}$

A recent paper by Heravi and Silver (2002) also assessed the stability of the DV price measure using (near-universe) scanner data. For selected electrical appliances, they compared DV measures obtained from estimates that use the entire dataset to those obtained using only current and base month observations. As is the case here, they found that the DV price measures calculated for their data are, for the most part, remarkably stable. ${ }^{8}$ The similarity in their specification to the fixed effects regression discussed above may explain the similarity in findings. Most of the characteristics used in their regression are specified as dummy variables: for example, whether the TV set has a flat screen tube, dolby stereo, a wide screen, digital imaging, etc. In addition, their regressions include "make" dummy variables to absorb the effect of any unobserved characteristics. In many respects, their regressions are also fixed effects regressions and that may explain the stability of their DV measures.

\section{Concluding Remarks}

Unstable hedonic coefficients do not necessarily translate into unstable DV price measures. In data sets where it is possible to define models to be homogeneous, DV measures are affected by unstable hedonic coefficients only when there is product turnover (i.e., when the particular time period contains missing prices). In that case, the hedonic regression imputes the missing price using the coefficients on the models' characteristics. In this data set, the stability of the hedonic coefficients appears to depend importantly on the particular specification given to the hedonic regression. In particular, a functional form advocated by Diewert(2001) and used by Aizcorbe, Corrado and Doms(2000) provides more stable DV measures than a more-typical specification. 


\section{REFERENCES:}

Aizcorbe, A., C. Corrado and M. Doms (2000) "Constructing Price and Quantity Indexes for High Technology Goods,” paper presented at CRIW Summer Institute, July.

Berndt, E. (1991) The Practice of Econometrics: Classic and Contemporary. Reading, MA: Addison-Wesley Publishing Co.

Berndt, E., E. Dulberger, N. Rappaport (2000) "Price and Quality of Desktop and Mobile Personal Computers: A Quarter Century of History," paper presented at CRIW Summer Institute, July.

Diewert, E. (2001) "Hedonic Regressions: A Consumer Theory Approach," in R. Feenstra and M. Shapiro, eds., Scanner Data and Price Indexes, Cambridge, Mass.: National Bureau of Economic Research.

Dulberger, E. (1989) "The Application of a Hedonic Model to a Quality Adjusted Price Index for Computer Processors." in D.W. Jorgenson and R. Landau, eds. Technology and Capital Formation: 37-75. Cambridge, Massachusetts: Massachusetts Institute of Technology Press.

Feenstra, R.C. (1995) "Exact Hedonic Price Indexes," Review of Economics and Statistics 77:634-654.

Grimm, B.T. (1998) "Price Indexes for Selected Semiconductors,1974-1996" Survey of Current Business 78(February):8-24.

Heravi, S. and M. Silver (2002) "On the Stability of Hedonic Coefficients and their Implications for Quality-Adjusted Price Change Measurement," Paper presented at the NBER Summer Institute. Cambridge, Mass.

Medoff, J. and C. Harless (2000) "Secrets of the GDP," in Grant's Interest Rate Observer, 18(10z01-4, May.

Pakes, A. (2002) "A Reconsideration of Hedonic Price Indices with an Application to PCs," paper presented at Brookings Workshop on Economic Measurement. Hedonic Price Indexes: Too Fast? Too Slow? Or Just Right?.” February.

Silver, M. (1999) "An Evaluation of the Use of Hedonic Regressions for Basic Components of Consumer Price Indexes,” Review of Income and Wealth 45(1):4156.

Triplett, J.E. (1987) "Hedonic Functions and Hedonic Indexes," The New Palgrave: $A$ Dictionary of Economics, M.M. Eatwell and P. Newman, eds. London: MacMillan.

Triplett, J.E. and R. McDonald (1977) "Assessing the Quality Error in Output Measures: The Case of Refrigerators," Review of Income and Wealth 23(2):137-156. 
Table 1. Estimated Hedonic Coefficients: Typical Specification

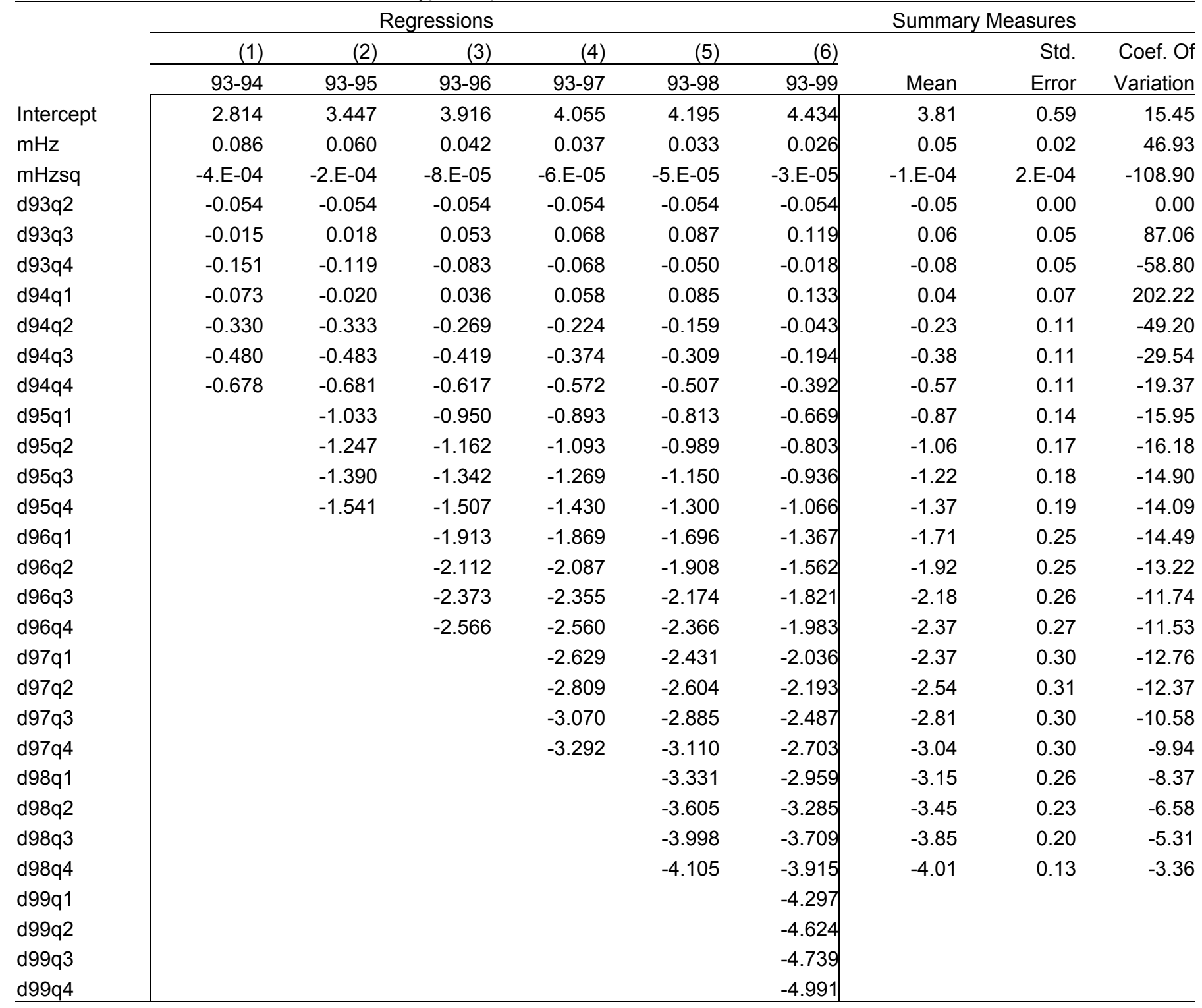

Source: Author's calculations 
Table 2. Dummy Variable Price Measures: Typical Specification.

\begin{tabular}{|c|c|c|c|c|c|c|c|c|c|}
\hline \multicolumn{7}{|c|}{ Regressions } & \multicolumn{3}{|c|}{ Summary Measures } \\
\hline & $(1)$ & $(2)$ & (3) & (4) & (5) & $(6)$ & & Std. & Coef. Of \\
\hline & $93-94$ & $93-95$ & $93-96$ & $93-97$ & $93-98$ & $93-99$ & Mean & Error & Variation \\
\hline $93 q 3$ & 3.97 & 7.40 & 11.28 & 12.95 & 15.06 & 18.84 & 13.1 & 4.3 & 32.5 \\
\hline $93 q 4$ & -12.78 & -12.78 & -12.78 & -12.78 & -12.78 & -12.78 & -12.8 & 0.0 & 0.0 \\
\hline $94 q 1$ & 8.14 & 10.43 & 12.64 & 13.49 & 14.51 & 16.29 & 13.5 & 2.2 & 16.2 \\
\hline $94 q 2$ & -22.64 & -26.89 & -26.23 & -24.57 & -21.68 & -16.18 & -23.1 & 4.4 & -18.9 \\
\hline $94 q 3$ & -13.97 & -13.97 & -13.97 & -13.97 & -13.97 & -13.97 & -14.0 & 0.0 & 0.0 \\
\hline $94 q 4$ & -17.94 & -17.94 & -17.94 & -17.94 & -17.94 & -17.94 & -17.9 & 0.0 & 0.0 \\
\hline $95 q 1$ & & -29.66 & -28.30 & -27.48 & -26.32 & -24.21 & -27.2 & 2.1 & -7.6 \\
\hline $95 q 2$ & & -19.25 & -19.16 & -18.08 & -16.17 & -12.58 & -17.0 & 2.8 & -16.4 \\
\hline $95 q 3$ & & -13.37 & -16.47 & -16.16 & -14.90 & -12.47 & -14.7 & 1.7 & -11.8 \\
\hline $95 q 4$ & & -14.03 & -15.20 & -14.84 & -13.92 & -12.18 & -14.0 & 1.2 & -8.3 \\
\hline $96 q 1$ & & & -33.34 & -35.54 & -32.68 & -25.95 & -31.9 & 4.1 & -13.0 \\
\hline $96 q 2$ & & & -18.08 & -19.56 & -19.11 & -17.77 & -18.6 & 0.8 & -4.5 \\
\hline $96 q 3$ & & & -22.96 & -23.52 & -23.33 & -22.79 & -23.2 & 0.3 & -1.4 \\
\hline $96 q 4$ & & & -17.54 & -18.56 & -17.47 & -14.98 & -17.1 & 1.5 & -8.9 \\
\hline $97 q 1$ & & & & -6.68 & -6.29 & -5.15 & -6.0 & 0.8 & -13.2 \\
\hline $97 q 2$ & & & & -16.47 & -15.92 & -14.52 & -15.6 & 1.0 & -6.5 \\
\hline $97 q 3$ & & & & -22.97 & -24.53 & -25.49 & -24.3 & 1.3 & -5.2 \\
\hline $97 q 4$ & & & & -19.88 & -20.15 & -19.39 & -19.8 & 0.4 & -2.0 \\
\hline $98 q 1$ & & & & & -19.83 & -22.60 & -21.2 & 2.0 & -9.2 \\
\hline $98 q 2$ & & & & & -23.96 & -27.81 & -25.9 & 2.7 & -10.5 \\
\hline $98 q 3$ & & & & & -32.51 & -34.56 & -33.5 & 1.5 & -4.3 \\
\hline $98 q 4$ & & & & & -10.13 & -18.60 & -14.4 & 6.0 & -41.7 \\
\hline $99 q 1$ & & & & & & -31.75 & & & \\
\hline $99 q 2$ & & & & & & -27.91 & & & \\
\hline $99 q 3$ & & & & & & -10.85 & & & \\
\hline $99 q 4$ & & & & & & -22.28 & & & \\
\hline
\end{tabular}

Source: Author's calculations 
Table 3. Dummy Variable Price Measures, Fixed-Effect Specification.

\begin{tabular}{|c|c|c|c|c|c|c|c|c|c|}
\hline & \multicolumn{6}{|c|}{ Regressions } & \multicolumn{3}{|c|}{ Summary Measures } \\
\hline & $(1)$ & $(2)$ & (3) & $(4)$ & $(5)$ & (6) & & Std. & Coef. Of \\
\hline & $93-94$ & $93-95$ & $93-96$ & $93-97$ & $93-98$ & $93-99$ & Mean & Error & Variation \\
\hline $93 q 3$ & -8.43 & -9.76 & -9.70 & -9.69 & -9.69 & -9.69 & -9.7 & 0.0 & -0.3 \\
\hline $93 q 4$ & -12.78 & -12.78 & -12.78 & -12.78 & -12.78 & -12.78 & -12.8 & 0.0 & 0.0 \\
\hline $94 q 1$ & -4.12 & -4.22 & -4.22 & -4.22 & -4.22 & -4.22 & -4.2 & 0.0 & -0.1 \\
\hline $94 q 2$ & -15.54 & -14.92 & -15.03 & -15.08 & -15.08 & -15.08 & -15.0 & 0.1 & -0.5 \\
\hline $94 q 3$ & -13.97 & -13.97 & -13.97 & -13.97 & -13.97 & -13.97 & -14.0 & 0.0 & 0.0 \\
\hline $94 q 4$ & -17.94 & -17.94 & -17.94 & -17.94 & -17.94 & -17.94 & -17.9 & 0.0 & 0.0 \\
\hline $95 q 1$ & & -33.56 & -34.10 & -34.10 & -34.12 & -34.12 & -34.0 & 0.2 & -0.7 \\
\hline $95 q 2$ & & -17.66 & -16.68 & -16.68 & -16.72 & -16.72 & -16.9 & 0.4 & -2.5 \\
\hline $95 q 3$ & & -21.88 & -20.96 & -20.65 & -20.55 & -20.55 & -20.9 & 0.6 & -2.7 \\
\hline $95 q 4$ & & -19.18 & -18.98 & -18.93 & -18.92 & -18.92 & -19.0 & 0.1 & -0.6 \\
\hline $96 q 1$ & & & -30.52 & -30.51 & -29.95 & -29.95 & -30.2 & 0.3 & -1.1 \\
\hline $96 q 2$ & & & -27.72 & -29.14 & -30.93 & -30.93 & -29.7 & 1.6 & -5.2 \\
\hline $96 q 3$ & & & -21.93 & -20.63 & -20.01 & -20.01 & -20.6 & 0.9 & -4.4 \\
\hline $96 q 4$ & & & -14.84 & -14.05 & -13.92 & -13.92 & -14.2 & 0.4 & -3.1 \\
\hline $97 q 1$ & & & & -10.01 & -6.32 & -6.33 & -7.6 & 2.1 & -28.2 \\
\hline $97 q 2$ & & & & -14.78 & -14.44 & -14.45 & -14.6 & 0.2 & -1.3 \\
\hline $97 q 3$ & & & & -25.20 & -21.24 & -21.24 & -22.6 & 2.3 & -10.1 \\
\hline $97 q 4$ & & & & -26.41 & -19.68 & -19.69 & -21.9 & 3.9 & -17.7 \\
\hline $98 q 1$ & & & & & -21.46 & -21.35 & -21.4 & 0.1 & -0.4 \\
\hline $98 q 2$ & & & & & -28.68 & -28.80 & -28.7 & 0.1 & -0.3 \\
\hline $98 q 3$ & & & & & -30.60 & -30.99 & -30.8 & 0.3 & -0.9 \\
\hline $98 q 4$ & & & & & -18.70 & -17.57 & -18.1 & 0.8 & -4.4 \\
\hline $99 q 1$ & & & & & & -29.36 & & & \\
\hline $99 q 2$ & & & & & & -15.10 & & & \\
\hline $99 q 3$ & & & & & & -25.97 & & & \\
\hline $99 q 4$ & & & & & & -22.66 & & & \\
\hline
\end{tabular}

Source: Author's calculations 
Chart 1.Hedonic Coefficients: Fixed-effects Specification

Coefficient of Variation Statistics

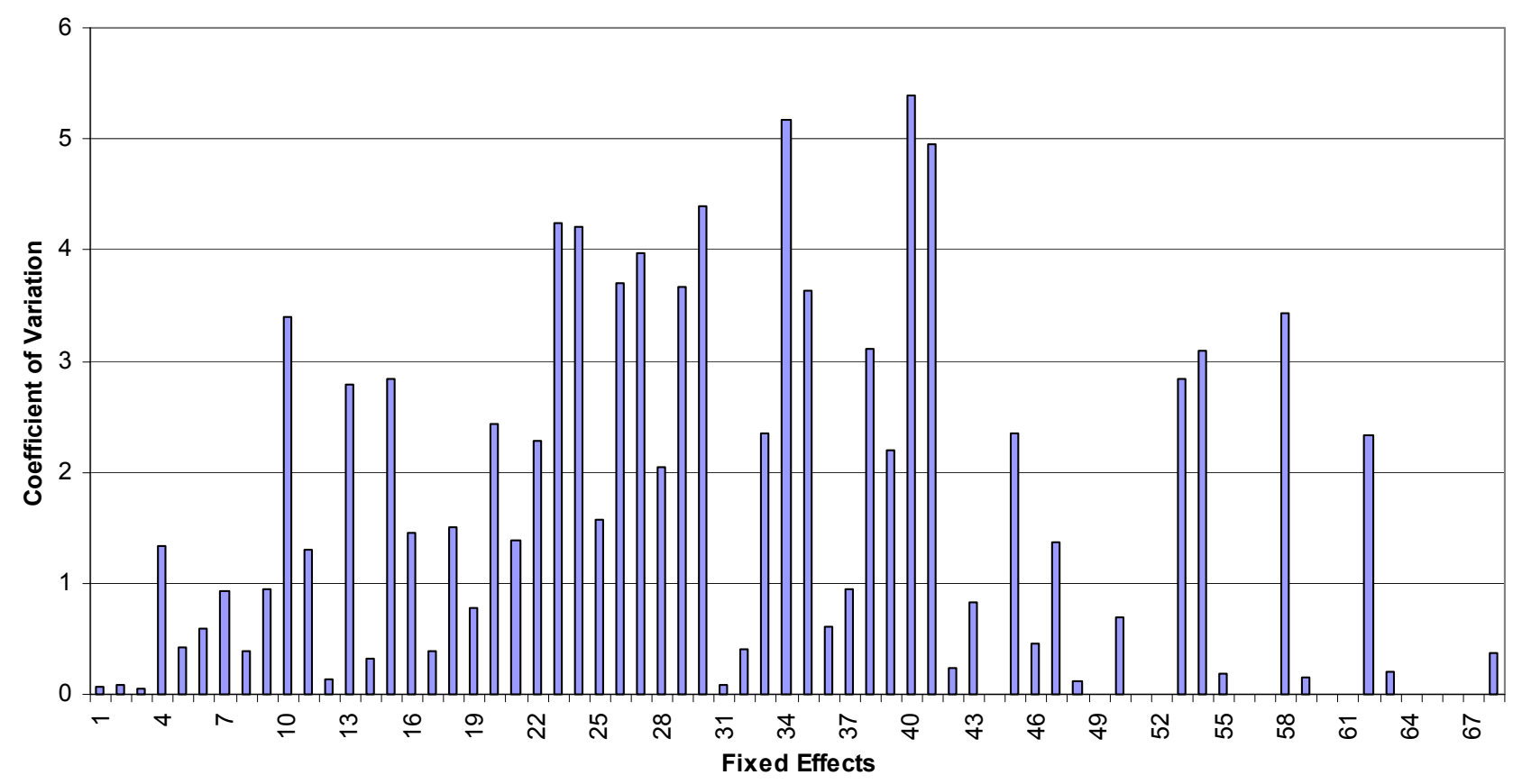


Footnotes

${ }^{1}$ See Triplett(1987) for an overview of hedonic regression techniques.

${ }^{2}$ The general relationship between dummy variable price measures and hedonic coefficients has been examined in Triplett and McDonald (1977), Berndt(1991), Feenstra(1995), Silver(1999), Aizcorbe, Corrado and Doms(2000), and Silver and Heravi (2002).

${ }^{3}$ This specification is "typical" in that it is log-linear with a quadratic functional form for the characteristics and no interactions between the time dummies and the characteristics. For a discussion of the potential problems with these features, see Medoff and Harless(2000). It is simplified in that it uses only one characteristic. Adding characteristics does not change any of the qualitatitive results that follow.

${ }^{4}$ This was demostrated in Aizcorbe, Corrado and Doms(2000) and noted in Heravi and Silver(2002).

${ }^{5}$ Speed is undeniably the characteristic that has the most influence over prices (see, for example, $\operatorname{Grimm}(1998)$.

${ }^{6}$ This works because the simple specification in (1) assumes that models have been defined to be homogeneous, so that their characteristics are constant over time.

${ }^{7}$ Some fixed-effect parameters in the three periods that constitute the exception were extremely unstable because they were based on one observation for the period of entry or exit. For example, there was a new chip introduced in the fourth quarter of 1997 and the fixed-effect coefficient for that chip that uses only data through 1997 is based on only one observation-that of the fourth quarter of that year.

${ }^{8}$ They found striking differences in the DV measures only in the sample for washing machines-the differences in the other four types of equipment were very small. 